\title{
TAFONOMÍA DE VERTEBRADOS HOLOCÉNICOS DEL SITIO ARQUEOLÓGICO CUEVA SALAMANCA 1 EN LA PUNA SALADA ARGENTINA.
}

\section{TAPHONOMY OF HOLOCENIC VERTEBRATES FROM CUEVA SALAMANCA 1 SITE IN THE ARGENTINEAN SALT PUNA.}

\author{
Antonela Marozzi ${ }^{1}$, Mariana Mondini² y Elizabeth Pintar ${ }^{3}$ \\ ${ }^{1}$ LaZTA, IDACOR-CONICET/ Museo de Antropología UNC, Av. H. Yrigoyen 174, (5000) \\ Córdoba, Argentina. Email: antonelamarozzi@yahoo.com.ar; \\ 2 LaZTA, IDACOR-CONICET/ Museo de Antropología UNC, Av. H. Yrigoyen 174, (5000) \\ Córdoba, Argentina; Universidad de Buenos Aires. Email: mmondini@filo.uba.ar; \\ ${ }^{3}$ Austin Community College, 11928 Stonehollow Drive, Austin, USA. Email: \\ lpintar@austincc.edu
}

Presentado: 16/12/2013 - Aceptado: 14/02/2015

\section{Resumen}

Se presentan los resultados del análisis tafonómico de restos de vertebrados procedentes del sitio arqueológico Cueva Salamanca 1 (CS1), situado en Antofagasta de la Sierra, Catamarca, a 3665 msnm, dentro de la Puna Salada argentina. Este sitio contiene ocupaciones de cazadoresrecolectores con dataciones del Holoceno Medio. Se trabajó con una muestra de especímenes identificables $(n=277)$ y una de especimenes no identificables $(n=514)$ de los diferentes estratos del sitio. La conservación de los materiales analizados es buena y no se observaron sesgos tafonómicos significativos. En general predominaron los procesos naturales intra-sitio, como la acción de humedad, por sobre procesos atmosféricos como la meteorización, aunque en ningún caso implicaron daños sustanciales. La alta frecuencia de trazas antrópicas en relación con la baja incidencia de las de carnívoros sugiere que los humanos fueron el principal agente de acumulación. La información obtenida se comparó con la de otros sitios arqueológicos, y con los datos paleoecológicos y paleoambientales disponibles para la región.

Palabras clave: tafonomía, Holoceno Medio, Puna Salada, sitio arqueológico Cueva Salamanca 1 


\begin{abstract}
This paper presents the taphonomic analyses of the archaeofaunal assemblage of Cueva Salamanca 1 (CS1) site in the Argentinean Salt Puna, Antofagasta de la Sierra, Catamarca located at 3665 masl. This site contains hunter-gatherer occupations dating to the mid-Holocene. A sample of identified $(n=277)$ and unidentified specimens $(n=514)$ from different stratigraphic levels from the site is examined. The preservation of the osteological specimens is good and does not reveal any significant taphonomic biases. In general, natural intra-site processes such as humidity predominated over atmospheric processes like weathering, although they did not substantially damage the assemblage. The high frequency of anthropic marks and the low frequency of carnivore marks at this site suggest that humans were the main accumulation agent. The information obtained was compared to that of other archaeological sites as well as with paleoecological and paleoenvironmental information available from the study area.
\end{abstract}

Keywords: taphonomy, Mid Holocene, Salt Puna, archaeological site Cueva Salamanca 1

\title{
Introducción y objetivos
}

Este trabajo presenta el análisis tafonómico realizado sobre los restos de vertebrados holocénicos procedentes del sitio arqueológico Cueva Salamanca 1 (CS1), situado en Antofagasta de la Sierra, provincia de Catamarca, en la Puna Salada argentina (Pintar 2004, 2009, 2012, 2014). El objetivo de este estudio consistió en evaluar la formación del registro arqueológico del sitio a partir de estos restos, con el fin de evaluar los potenciales sesgos que los procesos y agentes naturales pudieron imprimirle respecto de la información que ofrece sobre el comportamiento humano. Asimismo, se buscó evaluar la información paleoecológica que las trazas de estos procesos y agentes naturales ofrecen, en relación con la conocida a partir de otras fuentes y proxies. En términos más generales, buscamos aportar nueva información sobre la variabilidad tafonómica conocida para el Holoceno Medio en la Puna Salada.

Los registros paleoclimáticos para el Holoceno sugieren que en la Puna hubo variaciones en los niveles de humedad a escala regional. Posiblemente durante el Holoceno Medio se produjo una aridización generalizada hacia los 6000 AP, aunque los ambientes naturales de las vegas de las quebradas estrechas y profundas presentaron menor variabilidad ambiental que los valles extensos (Olivera et al. 2004; Olivera et al. 2006; Tchilinguirian y Morales 2013; Tchilinguirian y Olivera 2014; Tchilinguirian et al. 2005). Estas variaciones determinaron que algunas zonas tuvieran mayor disponibilidad de recursos y por lo tanto influyeron en la organización de los grupos cazadoresrecolectores y en la disposición de sitios arqueológicos y en la forma de utilización de éstos (Elkin 1996; Martínez et al. 2010; Mondini et al. 2013; Mondini et al. 2015; Núñez et al. 1999; Pintar 2009; Yacobaccio 2013). 


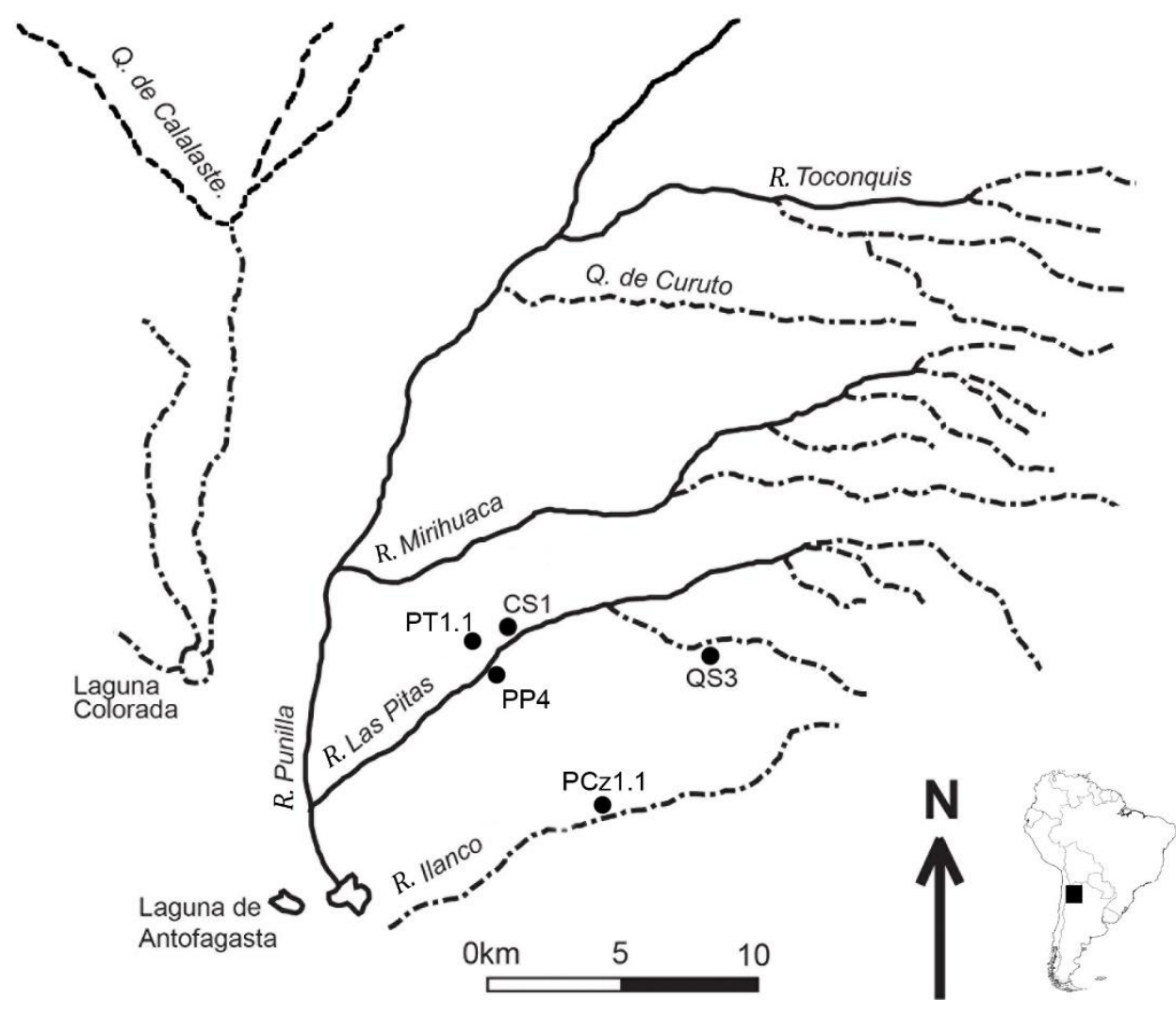

Figura 1: Localización de los sitios Cueva Salamanca 1 (CS1), Peña de las Trampas 1.1 (PT1.1), Punta de la Peña 4 (PP4), Peña de la Cruz 1.1 (PCz1.1) y Quebrada Seca 3 (QS3) en la cuenca de Antofagasta.

Las investigaciones arqueológicas realizadas hasta el momento en Antofagasta de la Sierra sugieren que los recursos fueron suficientes durante el Holoceno Medio como para sustentar poblaciones humanas (Martínez et al. 2010; Mondini et al. 2013; Pintar 2004, 2009, 2014; y bibliografía allí citada).

Posiblemente los sitios arqueológicos en la Puna Salada fueron ocupados desde comienzos de la primavera hasta fines del verano o comienzos del otoño, aunque también pudieron serlo en otros momentos del año. Entre los sitios arqueológicos con fechados radiocarbónicos para el Holoceno Medio se encuentra Cueva Salamanca 1 (CS1) (Capa 2). Este sitio está en una cueva a una altitud de $3665 \mathrm{msnm}$, en una corta y angosta cañada de acceso al farallón ignimbrítico en la margen izquierda del río Las Pitas, a unos $300 \mathrm{~m}$ del río y de la vega. Se encuentra $8 \mathrm{~km}$ al este de la localidad de Antofagasta de la Sierra (Figura 1). El sitio tiene aproximadamente $77 \mathrm{~m}^{2}$ y está orientado $170^{\circ}$ hacia el Sur (Pintar 2004). 
CSI presenta la mayoría de las ocupaciones arqueológicas en la primer mitad del Holoceno Medio (Tabla 1), entre ca. 8100 y 7400 años radiocarbónicos AP (Capas 2(10) a 2(3)), con otra hacia 6250 (Capa 2(2)) y otras de ca. 4500 AP (Capa 2(1)) (Pintar 2004, 2009, 2012, 2014). La Capa 1 de este sitio correspondería al Holoceno Tardío (Pintar 2004, 2014).

Otros sitios con fechados para el Holoceno Medio son Quebrada Seca 3 (QS3), Peñas de la Cruz 1.1 (PCz1.1), Peñas de las Trampas 1.1 (PT1.1) y Puntas de la Peña 4 (PP4) (Aschero 2000; Aschero et al. 1991; Martínez 2005; Martínez et al. 2004; Martínez et al. 2007; Martínez et al. 2010; Mondini et al. 2013; Urquiza 2008; Urquiza et al. 2009). Para el período de interés, hasta el momento se estudiaron tafonómicamente las arqueofaunas de dos sitios arqueológicos de Antofagasta de la Sierra, QS3, con ocupaciones a lo largo de todo el Holoceno, y PP4, con un fechado para comienzos del Holoceno Medio y otros más tardíos.

\begin{tabular}{|c|c|l|}
\hline Capa & Fechado & \multicolumn{1}{|c|}{ Taxones } \\
\hline $2(2)$ & $6250 \pm 70$ & $\begin{array}{l}\text { Camélido } \\
\text { Artiodáctilo }\end{array}$ \\
\hline $2(3)$ & $7410 \pm 100$ & $\begin{array}{l}\text { Camélido } \\
\text { Artiodáctilo }\end{array}$ \\
\hline $2(3)$ & $7630 \pm 40$ & $\begin{array}{l}\text { Camélido } \\
\text { Artiodáctilo }\end{array}$ \\
\hline $2(4)$ & $7500 \pm 60$ & $\begin{array}{l}\text { Camélido } \\
\text { ¿Cérvido? } \\
\text { Artiodáctilo }\end{array}$ \\
\hline $2(5)$ & $7550 \pm 60$ & $\begin{array}{l}\text { Camélido } \\
\text { Artiodáctilo }\end{array}$ \\
\hline $2(6)$ & $7540 \pm 50$ & $\begin{array}{l}\text { Camélido } \\
\text { Artiodáctilo }\end{array}$ \\
\hline $2(7)$ & $7620 \pm 60$ & $\begin{array}{l}\text { Camélido } \\
\text { Artiodáctilo } \\
\text { Chinchíllido }\end{array}$ \\
\hline $2(8)$ & $7870 \pm 50$ & $\begin{array}{l}\text { Camélido } \\
\text { Cérvido? } \\
\text { Artiodáctilo }\end{array}$ \\
\hline $2(9)$ & $7990 \pm 60$ & $\begin{array}{l}\text { Camélido } \\
\text { Artiodáctilo }\end{array}$ \\
\hline $2(10)$ & $8100 \pm 50$ & $\begin{array}{l}\text { Camélido } \\
\text { Artiodáctilo } \\
\text { Chinchíllido }\end{array}$ \\
\hline & & \\
\hline
\end{tabular}

Tabla 1: Estratigrafía, fechados (Pintar 2014) y fauna (Mondini et al. 2015) de CS1. 
El sitio arqueológico QS3 es el más estudiado hasta el momento (Aschero 2000; Aschero et al. 1991; entre otros). Los análisis faunísticos para el Holoceno Medio muestran una alta frecuencia de camélidos, tanto vicuñas (Vicugna vicugna) como guanacos (Lama guanicoe), estos últimos en menor proporción (Elkin 1996; Mondini 2003; Mondini y Elkin 2006, 2014; Mondini et al. 2013), además de fibras de "patrón llama" y un pelo de cérvido (Mondini et al. 2013; Reigadas 2006, 2010). También se identificaron roedores, especialmente chinchíllidos, además de aves, carnívoros e insectos (Elkin 1996; Mondini 2003; Mondini y Elkin 2006, 2014; Mondini et al. 2013). Los agentes tafonómicos predominantes, aunque con baja intensidad, fueron roedores, carnívoros y la meteorización (Elkin 1996; Mondini 2002, 2003; Mondini y Elkin 2006, 2014). La meteorización se produjo con más intensidad en el Holoceno Medio, constituyendo otra fuente de evidencia de las condiciones de mayor aridez en este período (Elkin 1996).

PP4 es un abrigo rocoso ubicado a escasos metros de CS1 en la otra margen del río Las Pitas. Los fechados radiocarbónicos (ca. 8900 AP, ca. 4100 AP y entre 3800 y 960 AP) sugieren discontinuidades ocupacionales (Aschero MS en Rodríguez 2004; Aschero 2005 en Urquiza et al. 2009). Este sitio presenta materiales zooarqueológicos con mal estado de conservación para las ocupaciones más antiguas, adjudicado a cambios en el pH y el flujo horizontal y vertical de fluidos corporales de origen animal en el sitio, dado que éste tiene como piso la roca madre que impide el drenaje. También se observaron eflorescencias salinas adheridas a los huesos, propias de pH básico (Urquiza 2008; Urquiza et al. 2009).

En este trabajo se analizó una muestra de los restos faunísticos de CS1 desde un punto de vista tafonómico. Se analizaron especímenes identificables e indeterminados para reconocer la actividad de los distintos agentes y procesos tafonómicos y su importancia relativa en los procesos de formación del registro de este sitio arqueológico. Este análisis permitió establecer relaciones con la información paleoecológica disponible de la región y evaluar los sesgos que se pueden producir en las interpretaciones zooarqueológicas.

\section{Materiales y métodos}

Los materiales arqueológicos de CS1 se extrajeron en excavaciones sucesivas realizadas desde el año 1996. Se recuperaron desechos líticos, instrumentos líticos y óseos, cueros, pelos, restos óseos y de otros tejidos animales, insectos, valvas y restos vegetales. En general los materiales presentan un buen estado de conservación, y las trazas de agentes naturales y antrópicas son observables claramente en los restos óseos (Pintar 2004, 2009, 2012, 2014). 
Para este trabajo se tomó una muestra de los restos óseos de los diferentes estratos de la Capa 2. No se consideraron aquí los materiales de la Capa 1, que correspondería al Holoceno Tardío (Pintar 2004, 2014). La muestra que se analizó corresponde a 0,75 $\mathrm{m}^{2}$ de cada capa, equivalente al $1 \%$ de la superficie total del sitio. Se analizaron los especímenes identificables en dicha muestra, así como una submuestra de especímenes indeterminados correspondiente a $0,25 \mathrm{~m}^{2}$ de las mismas cuadrículas para las Capas 2(2), 2(4), 2(6), 2(8) y 2(10) (Marozzi 2012). La muestra analizada consistió en 277 especímenes identificados anatómica y taxonómicamente y 514 especímenes indeterminados (Marozzi 2012; Marozzi et al. 2013; Mondini et al. 2013; Mondini et al. 2015). La muestra de especímenes identificados (NISP) corresponde principalmente a artiodáctilos, en su mayoría camélidos aunque también se identificaron dos especímenes correspondientes tentativamente a cérvidos juveniles. Los especímenes de artiodáctilos pertenecen a individuos no natos, neonatos, cría, juveniles y adultos. También se identificaron algunos especímenes correspondientes a roedores chinchíllidos juveniles o adultos.

Se identificaron los agentes y procesos tafonómicos que participaron en la formación del registro zooarqueológico en base a posibles sesgos en la representación de las partes esqueletarias, de acuerdo a su estructura y densidad mineral ósea y a las modificaciones óseas (Marozzi 2012; Marozzi y Mondini 2010; Marozzi et al. 2013; ver también Lyman 1994; Mengoni Goñalons 2010). La atrición mediada por la densidad ósea se evaluó en los camélidos a partir de la propuesta de Elkin (1995).

Para reconocer las trazas de los diferentes agentes y procesos tafonómicos se utilizaron lupas de mano de 10X y 15X y, en casos ambiguos, lupa binocular con aumentos entre 5X y 45X. Se identificaron los estadios de meteorización (Behrensmeyer 1978) y de conservación relativa de los materiales cuando no fue posible evaluar la meteorización debido a la acción de otros procesos físico-químicos como el quemado o debido al tamaño del espécimen o su asignación taxonómica. Se consideró un estado de conservación bueno cuando es semejante a los estadios cero y uno de meteorización, conservación regular cuando es semejante a los estadios dos y tres de meteorización y conservación mala cuando es análoga a los estadios cuatro y cinco (Mondini 2003). También se evaluó el grado de fragmentación y el tipo de fractura (Bonnichsen y Will 1980; Johnson 1985, entre otros) y se reconocieron los posibles daños producidos por quemado, agentes químicos, roedores, aves, carnívoros, humanos y pisoteo, entre otros (Fisher 1995; Lyman 1994; Mondini 2003).

\section{Resultados}

Los estratos en los que se identificó una proporción mayor de especímenes fueron la Capa 2(7) y la Capa 2(9), con más de 30\%NISP, y aquellos en los que se identificó una menor proporción de especímenes fueron la Capa 2(3) y Capa 2(5), con menos de 
10\%NISP (Figura 2). En la Capa 2(3) la muestra de especímenes identificables analizada es pequeña $(\mathrm{NISP}=6)$, y por lo tanto la interpretación es preliminar.

La conservación de los restos óseos fue mayoritariamente buena en todas las capas (Figura 2). En general, más del $70 \%$ de los especímenes se encontraban en estadio de meteorización $\leq 1$ o estado de conservación bueno, a excepción de la Capa 2(9), que presentó una proporción de especímenes en estado de conservación bueno algo menor al 50\%NISP. La Capa 2(2) presentó el mejor estado de conservación de los materiales, con más del $80 \%$ NISP en estado de conservación bueno.

No se observaron correlaciones significativas entre las frecuencias anatómicas y la densidad global ósea, a excepción de los camélidos juvenil-adultos de la Capa 2(8). En este grupo el coeficiente de correlación de Spearman sugiere una relación fuerte, positiva y significativa entre el \%MAU y la densidad mineral ósea $\left(\mathrm{r}_{\mathrm{s}}=0,85 ; \mathrm{p}=0,03\right)$. En varios grupos etarios o taxonómicos no se pudo calcular el coeficiente de correlación de Spearman debido al pequeño tamaño muestral, si bien la variada representación anatómica, que incluye una relativamente alta frecuencia de especímenes del esqueleto axial de los camélidos maduros, además de elementos frágiles de crías (Marozzi 2012; Marozzi et al. 2013; Mondini et al. 2015), y la baja incidencia de otras trazas tafonómicas (Figuras 2 y 4) sugieren que es improbable una atrición intensa.

Los especímenes indeterminados también se encontraron en buen estado de conservación (Figura 3). En general predominaron los especímenes correspondientes a taxones grandes en todos los estratos (Figura 4). Se identificaron especímenes con tejido compacto y esponjoso y especímenes formados sólo por uno de estos tejidos. La representación de tejido esponjoso en la muestra también es un indicador de su buen estado de conservación (Marozzi 2012).

La fragmentación fue muy importante en todas las capas, especialmente en las Capas 2(3), 2(4), 2(5), 2(6) y 2(9), en las que no se identificaron elementos completos (Figura 5). Las fracturas fueron predominantemente frescas, en algunos casos atribuibles a humanos a partir de líneas de evidencia como los hoyos o estrías de percusión asociados (Tabla 2). Con respecto a los especímenes indeterminados, sólo en las Capas 2(2) y 2(10) se identificaron trazas antrópicas que permiten atribuir las fracturas a este agente (Tabla 2). En muchos casos no fue posible identificar el tipo de fractura de estos especímenes debido al pequeño tamaño. En su mayoría, el largo máximo fue entre 0.5 y $5 \mathrm{~cm}$ (Figura 6). En la Capa 2(10), la frecuencia de especímenes menores a $0.5 \mathrm{~cm}$ fue evidentemente mayor al resto de los estratos $(>70 \%)$. La frecuencia de especímenes indeterminados mayores a $5 \mathrm{~cm}$ fue $<5 \%$ en todos los casos. 

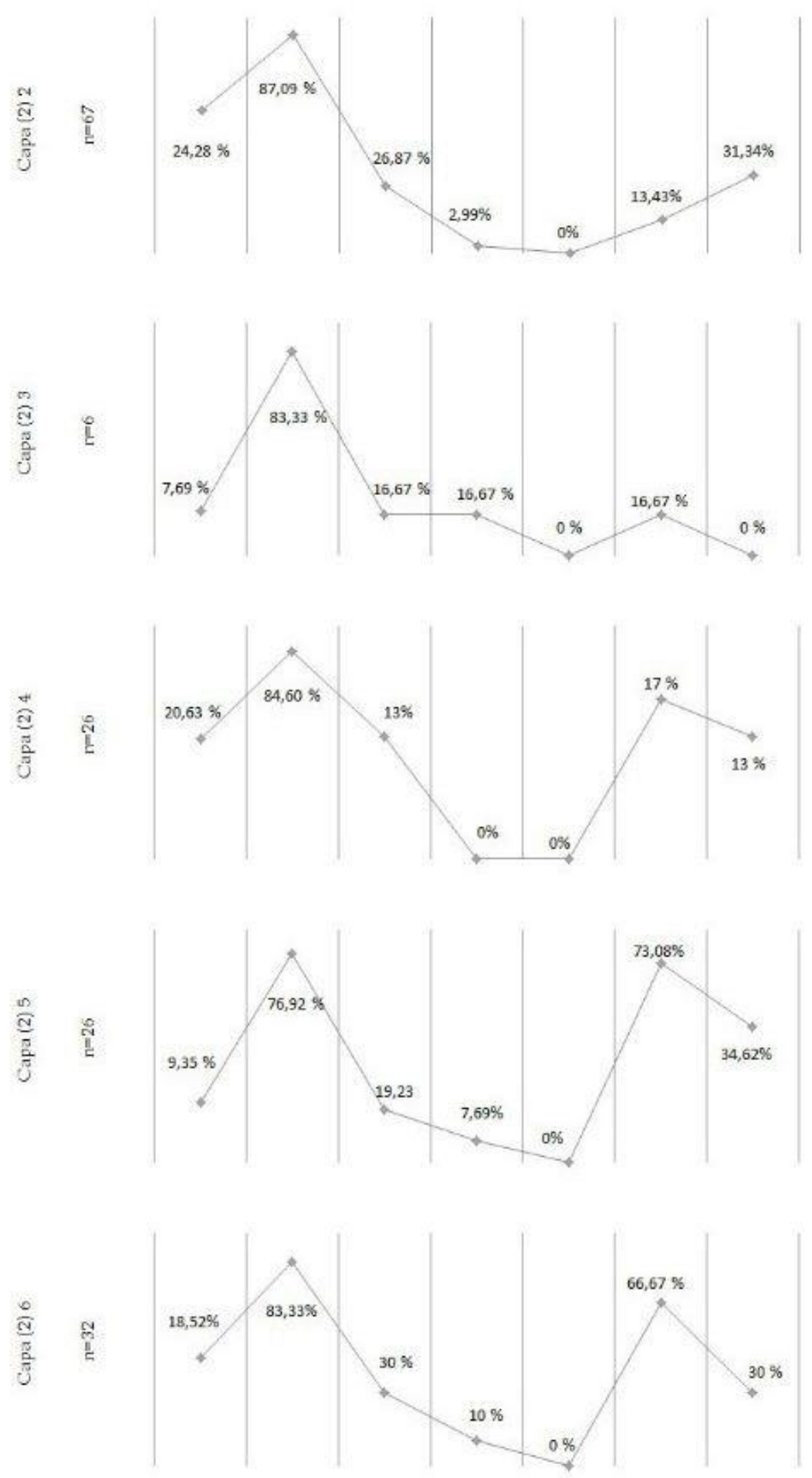

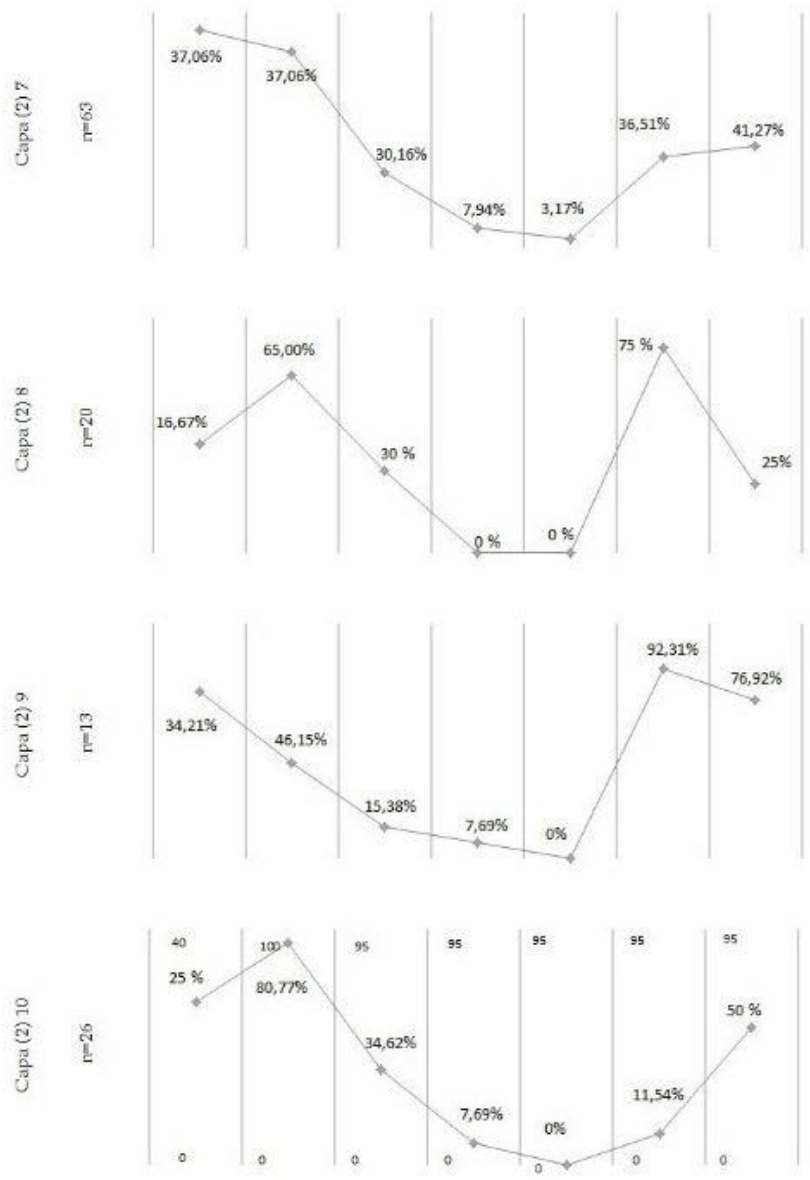

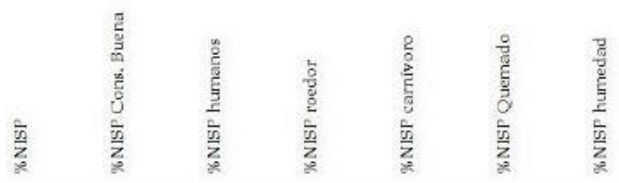

Figura 2: Tafograma de la frecuencia de trazas de agentes bióticos y abióticos en especímenes identificables anatómica y taxonómicamente. Abreviaturas: \%NISP: porcentaje del número de especímenes identifica-dos; \%NISP cons. buena: proporción de especíme-nes identificados con conservación buena; $\%$ NISP humanos: propor-ción de especímenes identificados con marcas de humanos; $\%$ NISP roedor: proporción de especímenes identifica-dos con marcas de roedor; \% NISP carnívo-ros: proporción de especímenes identifica-dos con marcas de carnívoros; $\%$ NISP quemado: proporción de especímenes identifica-dos con trazas de quema-do; $\%$ NISP humedad: proporción de especíme-nes identificados con marcas de humedad. 

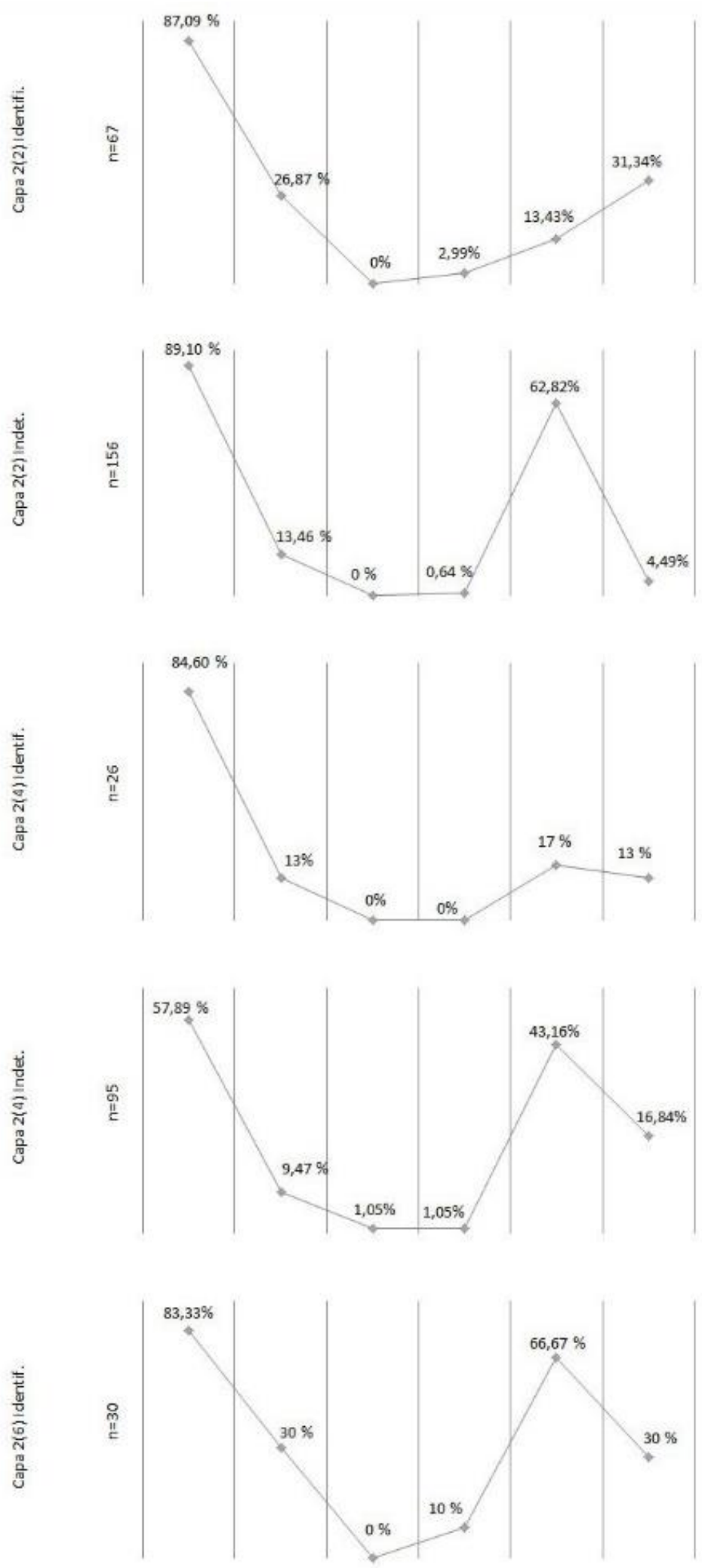

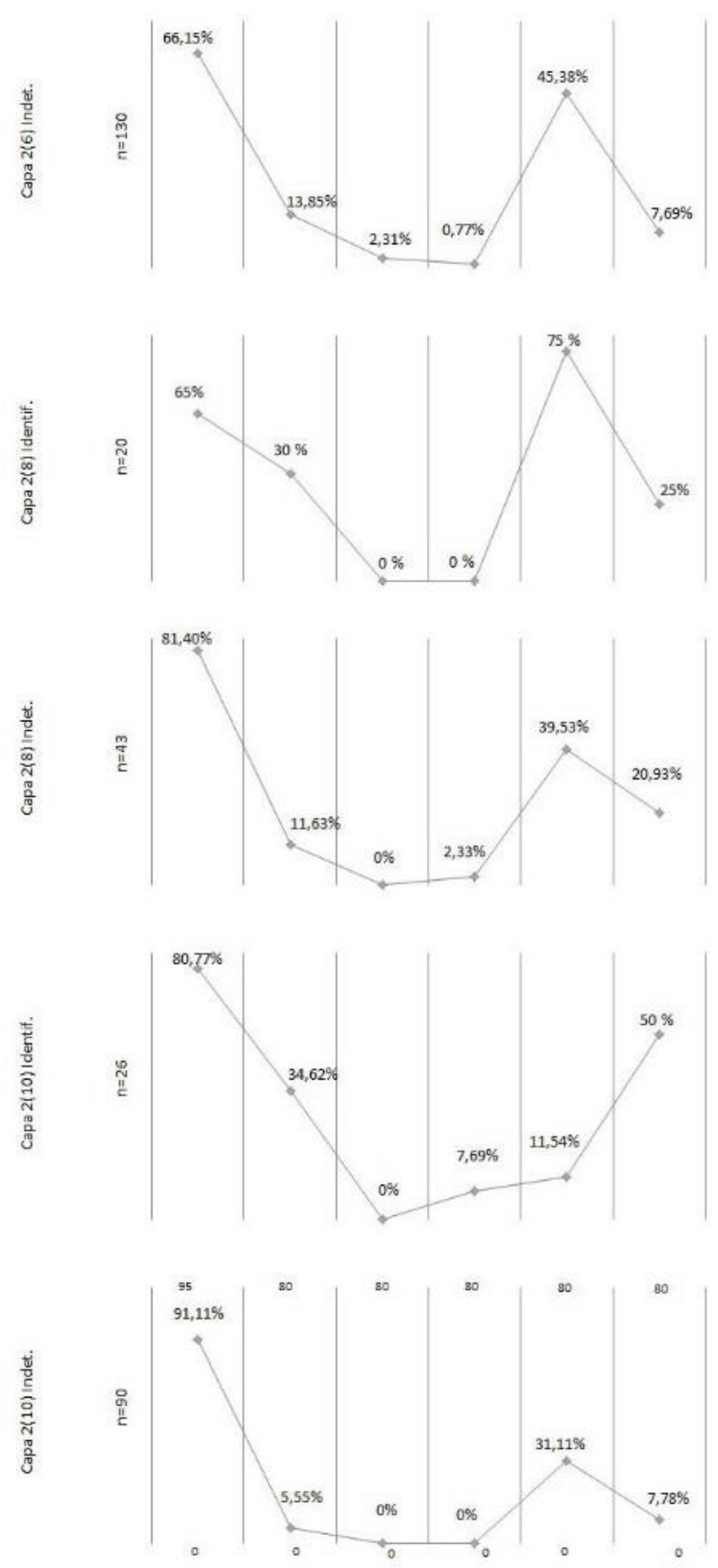

Figura 3: Tafograma comparativo de la frecuencia de trazas tafonómicas de agentes bióticos y abióticos en especímenes identificables anatómica y taxonómicamente y en especímenes indeterminados. Abreviaturas: \%Cons. buena: proporción de especímenes con conservación buena; \% Antrópico: proporción de especímenes con marcas de humanos; \%roedor: proporción de especímenes con marcas de roedor; \%carnívoros: proporción de especímenes con marcas de carnívoros; \%quemado: proporción de especímenes con trazas de quemado; \% procesos químicos: proporción de especímenes con trazas de procesos químicos.

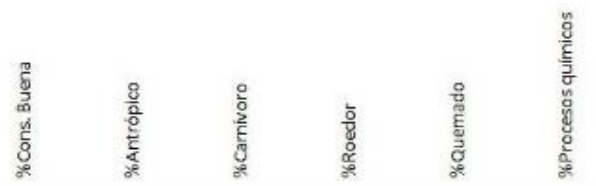




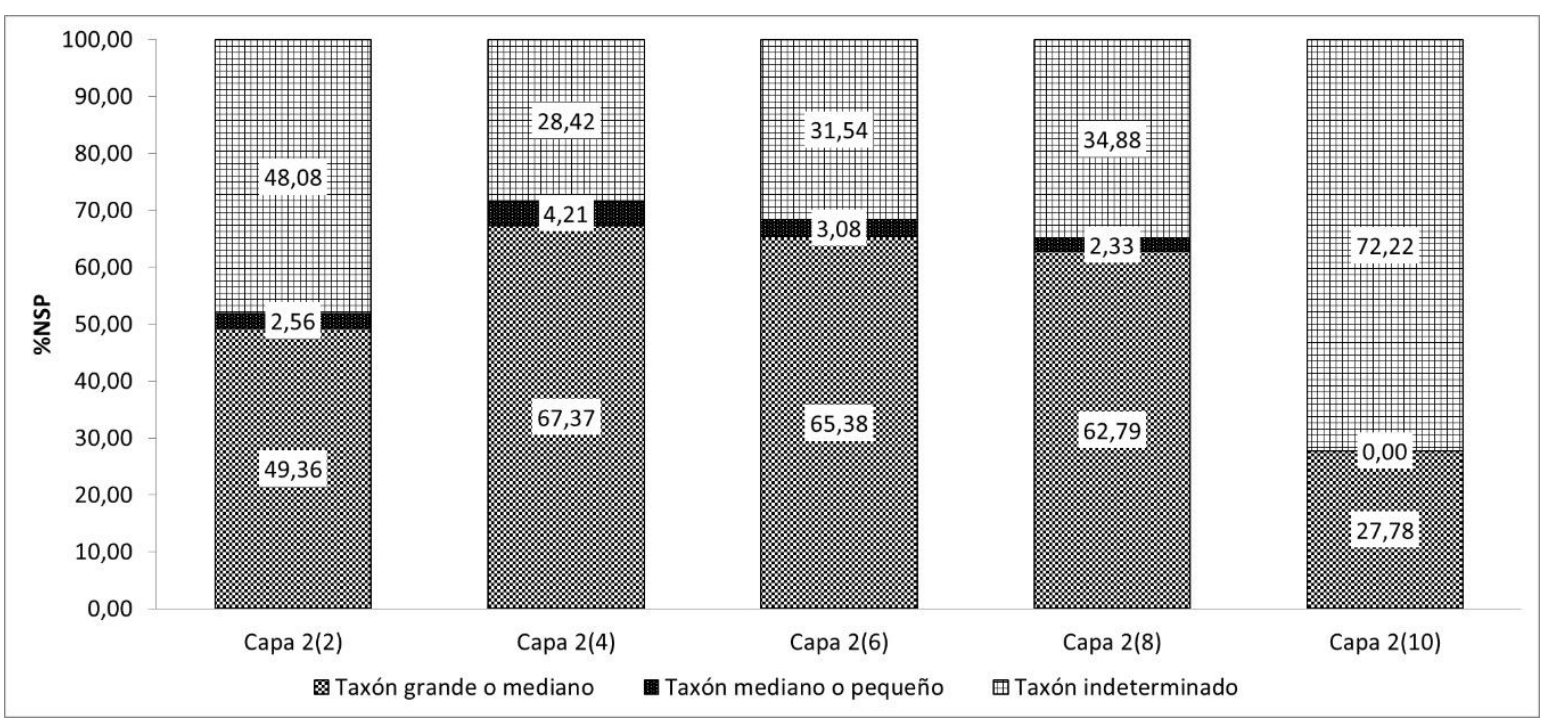

Figura 4: Tamaño de taxón en especímenes indeterminados.

\begin{tabular}{|c|c|c|c|c|c|c|c|c|c|}
\hline & \multicolumn{9}{|c|}{ Capa } \\
\hline & $\begin{array}{c}2(2) \\
\% \mathrm{NISP} / \\
\% \mathrm{NSP}\end{array}$ & $\begin{array}{c}2(3) \\
\% \text { NISP }\end{array}$ & $\begin{array}{c}2(4) \\
\% \text { NISP } / \\
\% \text { NSP }\end{array}$ & $\begin{array}{c}2(5) \\
\% \text { NISP }\end{array}$ & $\begin{array}{c}2(6) \\
\% \text { NISP } \\
/ \% \text { NSP }\end{array}$ & $\begin{array}{c}2(7) \\
\% \text { NISP }\end{array}$ & $\begin{array}{c}2(8) \\
\% \mathrm{NISP} \\
/ \% \mathrm{NSP}\end{array}$ & $\begin{array}{c}2(9) \\
\% \text { NISP }\end{array}$ & $\begin{array}{c}2(10) \\
\% \text { NISP/ } \\
\% \text { NSP }\end{array}$ \\
\hline $\begin{array}{l}\text { Fracturas frescas de } \\
\text { origen indeterminado }\end{array}$ & $\begin{array}{l}52.24 \\
31.41\end{array}$ & 83.33 & $\begin{array}{l}38.46 \\
38.95\end{array}$ & 42.31 & $\begin{array}{l}37.50 \\
39.23\end{array}$ & 38.10 & $\begin{array}{l}40.00 \\
51.16\end{array}$ & 76.92 & $\begin{array}{l}38.46 \\
12.22\end{array}$ \\
\hline $\begin{array}{l}\text { Fracturas frescas } \\
\text { antrópicas }\end{array}$ & $\begin{array}{c}25.37 \\
6.41\end{array}$ & 0.00 & $\begin{array}{c}42.31 \\
0.00\end{array}$ & 26.92 & $\begin{array}{c}18.75 \\
0.00\end{array}$ & 22.22 & $\begin{array}{c}15.00 \\
0.00\end{array}$ & 0.00 & $\begin{array}{l}34.62 \\
12.22\end{array}$ \\
\hline Fracturas secas & $\begin{array}{l}1.49 \\
0.64\end{array}$ & 0.00 & $\begin{array}{l}3.85 \\
0.00\end{array}$ & 34.62 & $\begin{array}{l}9.38 \\
0.00\end{array}$ & 7.94 & $\begin{array}{l}0.00 \\
2.33\end{array}$ & 0.00 & $\begin{array}{l}0.00 \\
2.22\end{array}$ \\
\hline $\begin{array}{l}\text { Fracturas } \\
\text { indeterminadas }\end{array}$ & $\begin{array}{l}5.97 \\
60.26 \\
\end{array}$ & 16.67 & $\begin{array}{l}11.54 \\
48.42\end{array}$ & 3.85 & $\begin{array}{l}34.38 \\
53.85\end{array}$ & 6.35 & $\begin{array}{l}15.00 \\
41.86\end{array}$ & 23.08 & $\begin{array}{l}23.08 \\
83.33\end{array}$ \\
\hline Remoción & $\begin{array}{l}4.48 \\
1.28\end{array}$ & 0.00 & $\begin{array}{l}11.54 \\
12.63\end{array}$ & 3.85 & $\begin{array}{c}12.50 \\
6.92\end{array}$ & 6.35 & $\begin{array}{l}0.00 \\
2.33\end{array}$ & 0.00 & $\begin{array}{l}0.00 \\
1.11\end{array}$ \\
\hline
\end{tabular}

Tabla 2: Proporción de especímenes identificables (\%NISP) e indeterminados $(\% \mathrm{NSP})$ con diferentes clases de fragmentación respecto del total.

Una proporción importante de los especímenes identificados presentaban evidencias de termoalteración, resultando en más del 60\%NISP en las Capas 2(4), 2(5), 2(6), 2(8) y 2(9). Particularmente en la Capa 2(9), 92\% de los especímenes identificados presentaban evidencias de haber sido sometidos a la acción del fuego (Figura 2). Entre los especímenes indeterminados, la mayor frecuencia de daños de quemado (62\%) se encontró en la Capa 2(2). En el resto de las muestras de especímenes indeterminados analizadas, la frecuencia de estas trazas fue $<45 \%$ (Figura 3 ). 
La actividad humana se identificó principalmente a partir de huellas de corte y percusión en huesos de artiodáctilos, camélidos en particular, y algunos de chinchíllidos. La mayor incidencia de trazas antrópicas se observó en la Capa 2(4) (50\%NISP), datada hacia los 7500 AP (Figura 2). En las demás muestras se observó una frecuencia de trazas antrópicas entre $20 \%$ NISP y $40 \%$ NISP, a excepción de las Capas 2(9) (15\%NISP) y 2(3) (16\% NISP), aunque en este último caso ello puede estar relacionado con el pequeño tamaño muestral (NISP=6).

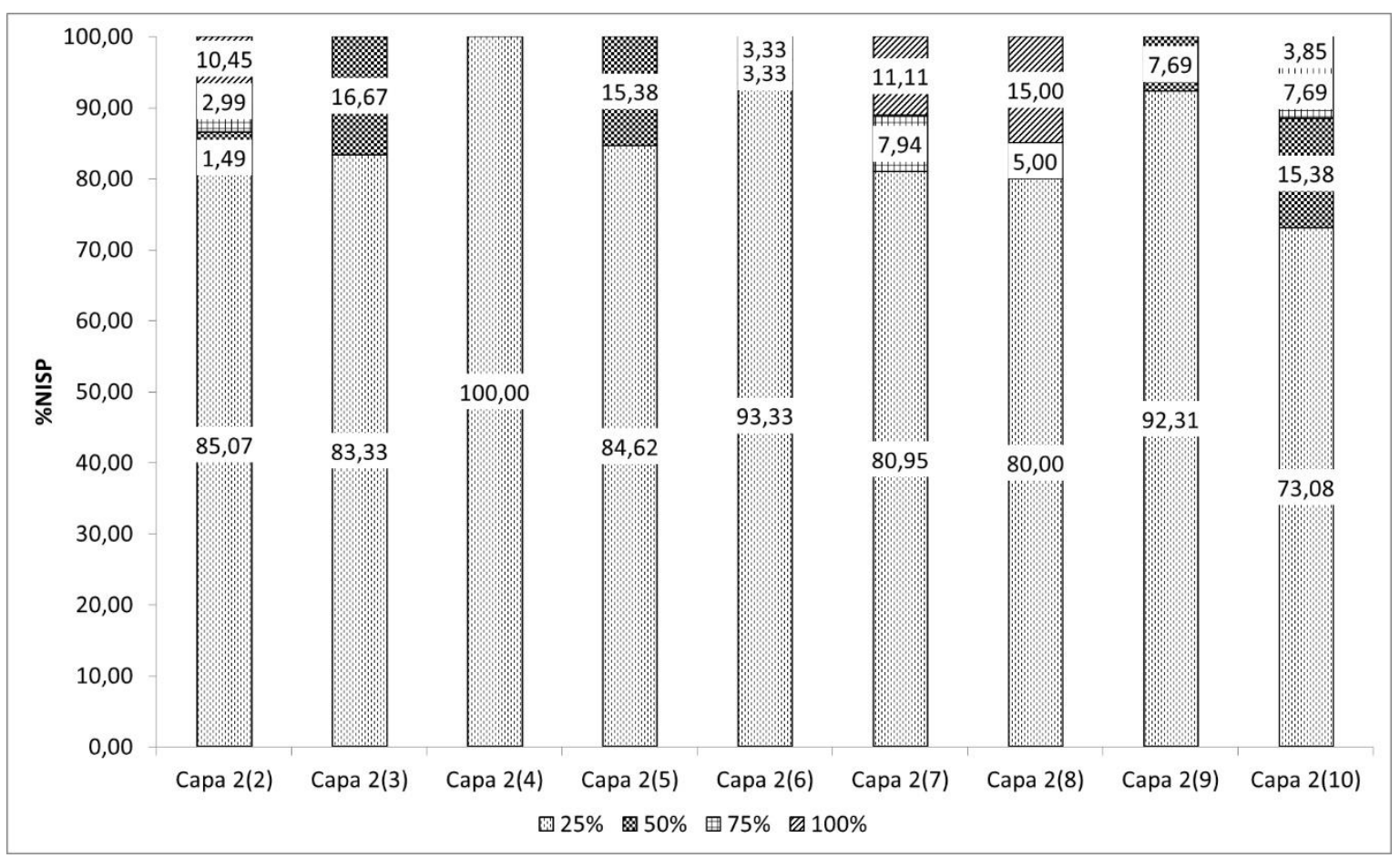

Figura 5: Completitud de los elementos representados por los especímenes identificados: desde elementos completos $(100 \%)$ hasta muy incompletos (25\% aprox. del elemento entero).

Las trazas humanas se encontraron en menor frecuencia en los especímenes indeterminados (Figura 3). Las Capas 2(2), 2(4), 2(6) y 2(8) presentaron aproximadamente entre el $9 \%$ y el 14\% de los especímenes con huellas de actividad humana. La Capa (10) presentó apenas algo más del 5\% de los especímenes indeterminados con estos daños. 


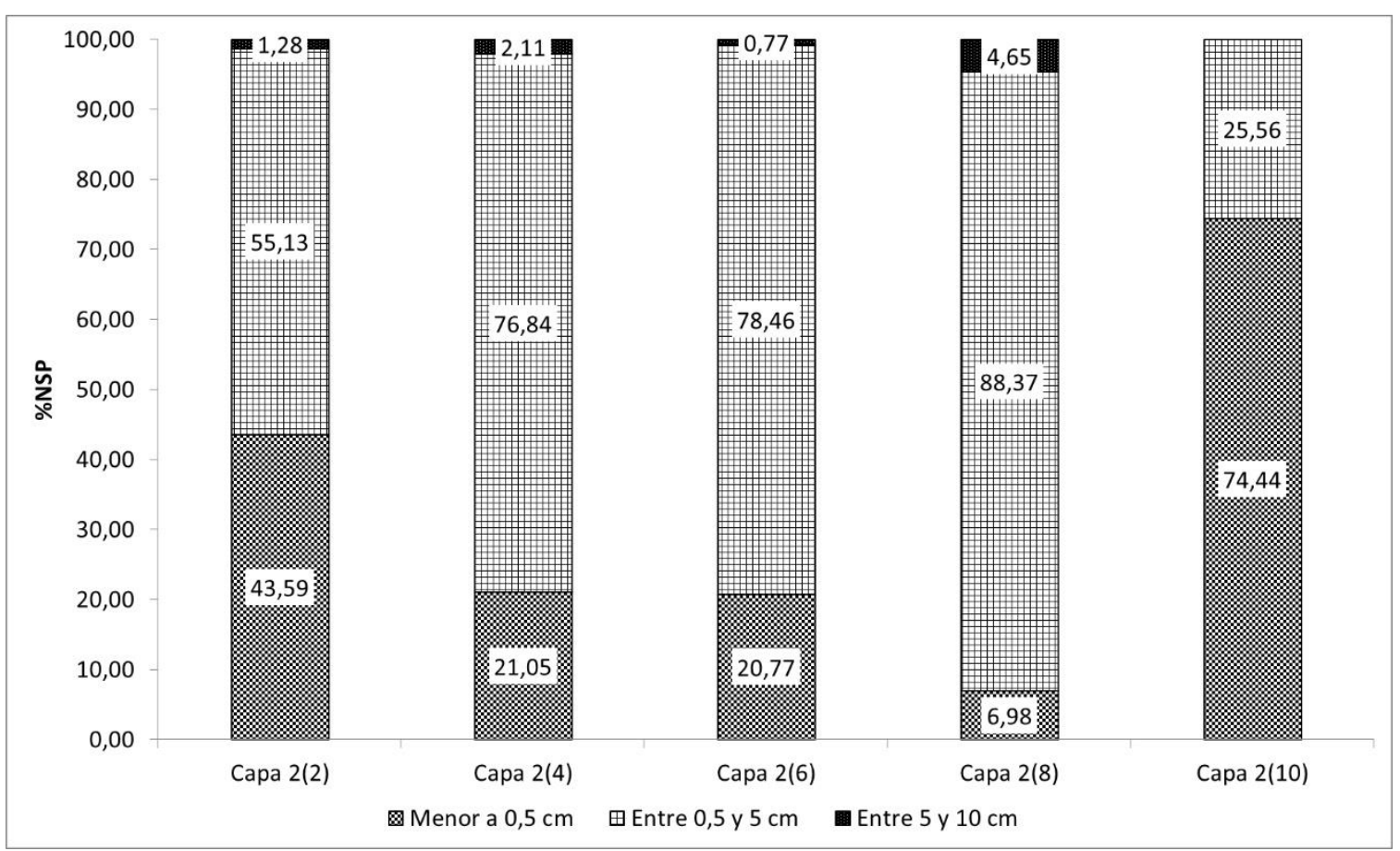

Figura 6: Proporción de especímenes indeterminados (\%NISP) por tamaño.

Entre los especímenes identificables se observaron marcas de roedor en la mayoría de las capas, aunque en mínimas proporciones (Figura 2). La Capa 2(6) tiene una proporción levemente mayor de este agente (ca. 9\%). Las Capas 2(4) y 2(8) no presentaron especímenes identificables con estas trazas, aunque se identificaron trazas de roedor en especímenes indeterminados correspondientes a estos estratos (Figura 3).

Es destacable que los carnívoros tuvieron una incidencia muy baja (Figuras 2 y 3 ). Se identificaron marcas y remoción por estos agentes sólo en dos costillas de camélidos de la Capa 2(7) (3,17\%NINSP). También presentan daños de mascado un espécimen indeterminado de la Capa 2(4) (1,05\% de este subconjunto), y registran daños de digestión dos especímenes indeterminados de la Capa 2(6) (2,31\%), todos ellos correspondientes a elementos del esqueleto axial.

Los daños producidos por humedad produjeron distintas trazas en cada capa (Figuras 2 y 4, Tabla 3). En la Capa 2(9) se observó la mayor proporción de estas trazas (>75\% NISP), y la menor incidencia de estos daños se observó en la Capa 2(8) (25\%NISP). En esta última capa, sin embargo, se registró la mayor proporción de daños químicos, posiblemente causados por humedad, entre los especímenes indeterminados ( $21 \%$ de la submuestra). En la Capa 2(3) no se identificaron daños por humedad, posiblemente debido al mínimo tamaño de la muestra $(\mathrm{NISP}=6)$. En las demás submuestras de especímenes indeterminados, la proporción de daños químicos varió entre 4\% y 17\% 
(Figura 3). Es interesante marcar que además de trazas diagnósticas asociadas a la acción de humedad, se identificaron huesos con hongos (Figura 7) en su superficie (Tabla 3). Sabemos, por un análisis preliminar con microscopio óptico (10X y 45X), que varios especímenes recolectados en la campaña de diciembre de 2010 también contenían hongos y en algunos casos, éstos estaban secos (Laura Domínguez, comunicación personal).

\begin{tabular}{|l|c|c|c|c|c|c|c|c|c|}
\hline & $\begin{array}{c}\text { Capa } \\
2(2)\end{array}$ & $\begin{array}{c}\text { Capa } \\
2(3)\end{array}$ & $\begin{array}{c}\text { Capa } \\
2(4)\end{array}$ & $\begin{array}{c}\text { Capa } \\
2(5)\end{array}$ & $\begin{array}{c}\text { Capa } \\
2(6)\end{array}$ & $\begin{array}{c}\text { Capa } \\
2(7)\end{array}$ & $\begin{array}{c}\text { Capa } \\
2(8)\end{array}$ & $\begin{array}{c}\text { Capa } \\
2(9)\end{array}$ & $\begin{array}{c}\text { Capa 2 } \\
(10)\end{array}$ \\
\hline Bordes redondeados & 1.49 & 0.00 & 0.00 & 0.00 & 0.00 & 4.76 & 0.00 & 0.00 & 3.85 \\
\hline Exfoliación superficial & 7.46 & 0.00 & 23.08 & 19.23 & 12.50 & 15.87 & 20.00 & 46.15 & 19.23 \\
\hline Superficie porosa & 7.46 & 0.00 & 11.54 & 15.38 & 0.00 & 6.35 & 0.00 & 0.00 & 11.54 \\
\hline $\begin{array}{l}\text { Aspecto oxidado de la capa } \\
\text { cortical }\end{array}$ & 13.43 & 0.00 & 19.23 & 11.54 & 6.25 & 23.81 & 5.00 & 7.69 & 23.08 \\
\hline $\begin{array}{l}\text { Separación de fibras del } \\
\text { hueso }\end{array}$ & 1.49 & 0.00 & 0.00 & 0.00 & 0.00 & 7.94 & 0.00 & 0.00 & 0.00 \\
\hline $\begin{array}{l}\text { Textura rugosa de la } \\
\text { superficie de fractura }\end{array}$ & 0.0 & 0.00 & 15.38 & 3.85 & 3.13 & 14.29 & 5.00 & 7.69 & 0.00 \\
\hline $\begin{array}{l}\text { Separación de capas del } \\
\text { hueso }\end{array}$ & 5.97 & 0.00 & 23.08 & 3.85 & 3.13 & 7.94 & 5.00 & 7.69 & 7.69 \\
\hline $\begin{array}{l}\text { Depositaciones de } \\
\text { manganeso }\end{array}$ & 20.90 & 0.00 & 3.85 & 7.69 & 0.00 & 1.59 & 0.00 & 15.38 & 23.08 \\
\hline Hongos & 2.99 & 0.00 & 19.23 & 19.23 & 15.63 & 17.46 & 10.00 & 30.77 & 11.54 \\
\hline $\begin{array}{l}\text { Depositaciones de } \\
\text { carbonato de calcio }\end{array}$ & 0.00 & 0.00 & 0.00 & 3.85 & 9.38 & 4.76 & 5.00 & 38.46 & 0.00 \\
\hline
\end{tabular}

Tabla 3: Proporción de especímenes identificables (\%NISP) con diferentes daños relacionados con condiciones de humedad respecto del NISP total.

\section{Discusión}

Aunque los resultados presentados son parciales, pueden considerarse como representativos de la historia tafonómica de las arqueofaunas de CS1. Los datos obtenidos son evaluados en función de los sesgos tafonómicos que pueden influir en la interpretación zooarqueológica y se los relaciona con la información paleoecológica disponible.

Los materiales óseos de CS1 se encontraban en buen estado de conservación y los especímenes en los que se pudo evaluar la meteorización presentaron mayormente estadios 0 y 1 de la escala de Behrensmeyer (1978). Los restos analizados sufrieron una exposición relativamente baja a los factores atmosféricos, especialmente a la radiación solar, y posiblemente las condiciones pre-enterramiento fueron bastante estables. La meteorización es aún menor que en el vecino sitio QS3, y no parece ser un agente importante de fragmentación. En QS3 se observó durante el Holoceno Medio una mayor proporción de especímenes meteorizados que en ocupaciones previas y subsiguientes, posiblemente debido al proceso de aridización que caracteriza a ese período (Elkin 1996). El buen estado 
de conservación de los materiales de CS1, en cambio, parece estar favorecido por el ambiente interno de la cueva, que no recibe exposición solar directa en ningún momento del día. Posiblemente eso hizo que la mayor aridez de este período no influyera sobre la conservación de los materiales de la misma forma que en QS3.

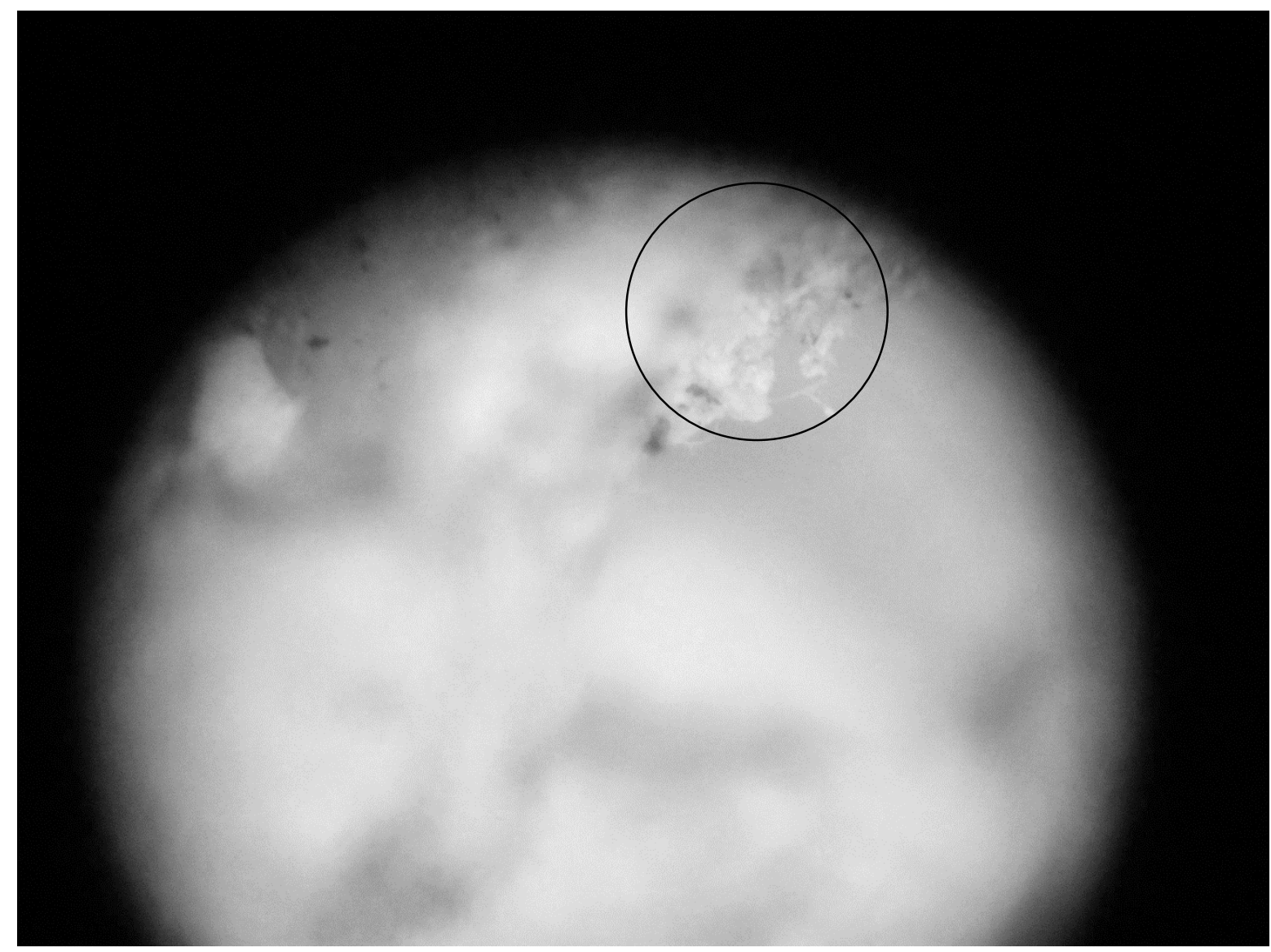

Figura 7: Espécimen óseo con hongos. Se marcan con un círculo las hifas fúngicas.

(Capa 2(4) Cuadrícula G3).

Sólo en la Capa 2(8) se identificaron indicios de atrición mediada por la densidad ósea. Sin embargo, es necesario tener en cuenta que en algunos casos el transporte diferencial por humanos puede dar resultados semejantes a los obtenidos en esta muestra, como es el caso en los conjuntos no transportados con utilidad inversa o con utilidad global o gourmet (Lyman 1994). Teniendo en cuenta que ésta es precisamente una de las capas con mayor proporción de daños antrópicos, y presenta además muy baja incidencia de trazas de agentes atricionales (Figura 2), lo último es lo más probable. 
En CS1 se observó una mayor acción de procesos asociados a la presencia de humedad (Tabla 3), a diferencia de otros sitios de la Puna como QS3. Se identificaron huesos con depositaciones de manganeso y de carbonato de calcio. Estas trazas, conjuntamente con otros daños como la exfoliación y los cambios de coloración y textura, sugieren un microambiente más húmedo en el interior de la cueva con relación al medio circundante, que favorece reacciones químicas. En los escasos especímenes con conservación regular, ésta parece estar más influenciada por la humedad interna de la cueva que por la meteorización.

En la ocupación correspondiente al Holoceno Medio del vecino sitio PP4, como vimos, se observaron materiales arqueológicos en mal estado de conservación, posiblemente debido a variaciones en el $\mathrm{pH}$ y el flujo de fluidos animales en el sitio (Urquiza 2008; Urquiza et al. 2009). Dado que CS1 no presenta estas características, probablemente los daños producidos en los huesos por humedad estén asociados al $\mathrm{pH}$ del sedimento y el escurrimiento del agua de las precipitaciones en la cueva.

La identificación de hongos en los materiales resulta novedosa en la región (Tabla 3, Figura 7). Posiblemente al menos algunos colonizaron los huesos cuando estaban todavía depositados en la cueva más que durante su almacenamiento post-recolección. En general, de acuerdo a la bibliografía, los estudios de microorganismos en fauna arqueológica se realizaron a través de análisis histológicos, y no por observación directa sino más bien a través de la identificación de trazas diagnósticas (Blumenschine et al. 2007; Child 1995; Davis 1998; Fernández-Jalvo et al. 2002; Jans et al. 2004, entre otros). En los materiales analizados aquí, los hongos se detectaron de forma directa, utilizando lupa binocular. Es por esto que es necesario abrir una nueva ronda de investigaciones que giren en torno a las modificaciones histológicas y bioquímicas que los materiales pueden presentar asociadas a esta clase de procesos.

La proporción de especímenes quemados fue muy notoria en las Capas 2(4), 2(5), 2(6), 2(8) y 2(9). Teniendo en cuenta el contexto de la Puna, los incendios naturales son poco probables y posiblemente estos especímenes hayan sido quemados por humanos, no necesariamente de forma intencional.

La fauna identificada en CS1, caracterizada principalmente por artiodáctilos, y más específicamente camélidos, presentó huellas de actividad antrópica tanto en los juveniladultos como en las crías (Marozzi et al. 2013; Mondini y Elkin 2014; Mondini et al. 2013; Mondini et al. 2015). Aunque no se pudo establecer el agente de acumulación y consumo de los individuos no natos, lo más probable es que hayan sido humanos teniendo en cuenta el contexto y la evidencia de otros sitios arqueológicos del área (Elkin 1996; Mondini 2002, 2003). La observación de huellas antrópicas en algunos especímenes de guanacos, sumada a la evidencia de QS3 (Elkin 1996; Mondini 2003; Mondini y Elkin 
2014; Mondini et al. 2013; Mondini et al. 2015), sugiere que esta especie estaba presente en la región y fue explotada por los humanos, aunque no hay registros actuales de su presencia en el área. Teniendo en cuenta las características de su distribución y su ecología en la actualidad, probablemente la ausencia de guanaco en Antofagasta de la Sierra en el presente se deba a un proceso de retracción de su rango y extinción local (Mondini y Elkin 2006).

En la muestra analizada también se encontraron roedores chinchíllidos en las Capas 2(7) y 2(10) (Marozzi et al. 2013; Mondini y Elkin 2014; Mondini et al. 2013; Mondini et al. 2015). En uno de los especímenes, una pelvis, se observaron huellas antrópicas de corte, lo que indica que este recurso también fue explotado por humanos en el pasado, y que éstos serían su agente acumulador, al menos en este caso. Otros sitios de Antofagasta de la Sierra, como QS3, y de la Puna en general también presentan restos de chinchíllidos, muchas veces con trazas de explotación humana aunque la frecuencia de utilización de este recurso fue menor durante en Holoceno Medio que en el Holoceno Temprano (Elkin 1996; López 2008; Yacobaccio et al. 2007). En CS1, la menor representación arqueológica de taxones pequeños se observa en los especímenes identificables (Mondini y Elkin 2014; Mondini et al. 2013; Mondini et al. 2015) y también en los especímenes indeterminados (Figura 4).

Los roedores también pueden ser sujeto de acción tafonómica y producir perturbaciones en los sitios arqueológicos debido a la formación de madrigueras que generan desplazamientos espaciales y modificar los especímenes óseos por mascado relacionado al desgate de sus incisivos, en continuo crecimiento (Lyman $1994 \mathrm{y}$ bibliografía allí citada). La ausencia de madrigueras de roedor en la estratigrafía de CS1, sumada a la escasa incidencia de las marcas de dientes en estas arqueofaunas, sugiere una baja probabilidad de desplazamientos de importancia en este sitio, previamente al primer enterramiento o a posteriori.

El predominio de fracturas frescas tanto en materiales identificables como en indeterminados, y su asociación a huellas antrópicas en muchos casos, sugieren que los humanos fueron el principal agente de fragmentación de la muestra analizada. Posiblemente muchas de las fracturas frescas por agente indeterminado también hayan sido causadas por humanos debido a que éstos fueron el principal agente biótico. Se sugirió que le elevada fragmentación de los materiales en QS3 se debe a la utilización de grasa ósea y de médula (Elkin 1996; Mohn 2010). Posiblemente ésta también sea la causa en CS1 (Mondini et al. 2015). Por otra parte, es poco probable que los carnívoros de la Puna (principalmente los zorros) puedan fragmentar sistemáticamente los huesos de los artiodáctilos, dado que tienen mandíbulas pequeñas y un relativamente bajo poder masticatorio (Mondini 2001, 2002, 2003, 2007). 
Entre los agentes acumuladores, aquellos más ambiguos respecto de los humanos son precisamente los mamíferos carnívoros (Binford 1981; Gifford 1981, entre otros). La historia tafonómica inferida para las muestras analizadas sugiere que los humanos fueron el agente acumulador más probable del registro faunístico de CS1 según el modelo comparativo sobre la acumulación antrópica y la de carnívoros planteado por Mondini (2003). Aunque no podemos descartar la acción de carnívoros en la formación del registro arqueológico de CS1, ésta es sumamente escasa, incluso aún menos que en QS3 y otros sitios de la Puna (Mondini 2002, 2003), y no habría producido sesgos tafonómicos significativos ni por modificación, ni por atrición, ni por adición.

La actividad de carnívoros se observó entre los 7600 y los 7500 años AP (Capas 2(4), 2(6) y 2(7)), según la muestra analizada, aunque en diversas capas se hallaron materiales escatológicos de estos agentes. Las trazas identificadas en las Capas 2(4) y 2(7) consisten en daños de mascado, y en la Capa 2(6) se identificaron especímenes con daños de digestión. En general los daños observados fueron sutiles, posiblemente causados por zorros, dado que los pumas dejan trazas más conspicuas (Mondini y Muñoz 2008). Los especímenes con trazas de carnívoros pertenecían en su mayoría a taxones grandes. Resulta poco probable que los zorros sean predadores de mamíferos grandes y posiblemente consumieron estas presas por carroñeo a partir de presas cazadas por predadores de mayor tamaño como los humanos (Mondini 2001, 2003, 2004). Esto está sustentado en CS1 por la baja incidencia de trazas de carnívoros, aún menor que en QS3, y su preferencia por los taxones grandes.

En algún momento del Holoceno Medio, los carnívoros, probablemente zorros, aprovecharon así este sitio, aunque el uso de la cueva por estos agentes habría sido muy escaso. Además, habría sido usada como fuente de alimentación más que como destino, dado que las madrigueras utilizadas por zorros suelen tener dimensiones menores a las utilizadas por humanos como refugio (Mondini 2003, 2005). Asimismo, la utilización de abrigos rocosos como fuente de alimentación por parte de los carnívoros deja menos trazas que la acumulación (Mondini 1995, 2001, 2003), y la buena integridad anatómica de la muestra no sugiere atrición por este agente. En síntesis, la acción de carnívoros en este sitio es muy baja y, sumada a otros conjuntos conocidos para este período, sugiere que la Puna fue durante el Holoceno Medio un ambiente con relativamente baja saturación de carnívoros (Mondini 2003, 2004).

\section{Conclusiones}

La tafonomía de CS1 es consistente con los análisis tafonómicos de QS3 y otros sitios de Antofagasta de la Sierra y de la Puna en general, en el sentido de que sugiere una buena conservación de los materiales y baja acción de carnívoros y roedores. 
En líneas generales, se puede proponer que el principal agente biótico que participó en la formación de CS1 fueron los humanos, y la participación de otros agentes y procesos fue poco significativa. La incidencia de trazas de carnívoros en este sitio es aún más baja que en otros sitios de la Puna (Mondini 2002, 2003, 2004), lo cual brinda nuevas evidencias en torno a la discusión de la estructura de las comunidades de predadores de esta región. Los carnívoros que dejaron trazas en los especímenes óseos de la región serían en su mayoría zorros, que posiblemente carroñaron los restos luego de la utilización humana de los mismos (Mondini 2002, 2003, 2004).

Entre los agentes abióticos predominaron los procesos relacionados con la presencia de humedad al interior de la cueva, y por lo tanto relacionados específicamente al ambiente interno de la misma. La identificación de hongos resulta novedosa para la región tanto desde una perspectiva microambiental como de conservación de los materiales. En este sentido, es interesante realizar estudios microscópicos y físicoquímicos para comprender el alcance de este agente.

Todas estas líneas de evidencia sugieren que fueron grupos humanos los principales agentes que formaron el registro arqueofaunístico de CS1, siendo la participación de otros agentes poco significativa. Esto permite reducir posibles ambigüedades al momento de evaluar la utilización de los recursos naturales por este agente, y el registro zooarqueológico del sitio puede ser considerado como una vía adecuada para comprender la utilización de los recursos por los grupos humanos que habitaron la Puna Salada en el Holoceno Medio. El estudio de CS1 brindó nuevos aportes a la comprensión del pasado reciente de la Puna en general y de Antofagasta de la Sierra en particular. Esto permite concebir una mayor variabilidad desde los puntos de vista tafonómico, arqueológico y paleoecológico que la conocida hasta el momento. Este análisis abrió además una nueva ronda de preguntas que deben ser abordadas desde una perspectiva interdisciplinaria para comprender las comunidades faunísticas así como otras características ambientales del pasado reciente en la región.

Agradecimientos: Este trabajo se realizó en el marco de proyectos de investigación financiados por la Universidad de Buenos Aires (UBACyT F445, 2008-2010; UBACyT 20020090200027, 2010-2012, y UBACyT 2002011010001, 2012-2015), la Universidad Nacional de Córdoba (SECyT 069/08, 2008-2009; 05/F719, 2010-2011, y 162/2012, 20122013), CONICET (PIP 11220100100208, 2011-2013) y MINCyT Córdoba (PID 000113/2011, 2013-2014). También nos gustaría agradecer a Laura Domínguez, quien colaboró con la identificación de hongos, y a Raúl Lira, que colaboró con la identificación de depositaciones de carbonato de calcio. 


\section{Bibliografía citada}

Aschero, C.

2000 El poblamiento del territorio. En Nueva Historia Argentina, Tomo 1: Los Pueblos Originarios y la Conquista, M. Tarragó (ed.), pp. 17-59. Editorial Sudamericana, Buenos Aires.

Aschero, C.; Elkin, D. y E. Pintar

1991 Aprovechamiento de recursos faunísticos y producción lítica en el Precerámico Tardío. Un caso de estudio: Quebrada Seca 3 (Puna Meridional Argentina). Actas del XI Congreso Nacional de Arqueología Chilena 2: 101-114. Sociedad Chilena de Arqueología, Santiago de Chile.

Behrensmeyer, A.

1978 Taphonomic and ecologic information from bone weathering. Paleobiology 4: 150162.

Binford, L.

1981 Bones: Ancient Men and Modern Myths. Academic Press, New York.

Blumenschine, R.; Prassack, K.; Kreger, C. y M. Pante

2007 Carnivore tooth-marks, microbial bioerosion, and the invalidation of DomínguezRodrigo and Barba's (2006) test of Oldowan hominin scavenging behavior. Authors' reply. Journal of Human Evolution 53: 420-433.

Bonnichsen, R. y R. Will

1980 Cultural modification of bone: the experimental approach in faunal analysis. En Mammalian Osteology, M. Gilbert (ed.), pp. 7-30. Missouri Archaeological Society, Columbia.

Child, A.

1995 Microbial taphonomy of archaeological bone. Studies in Conservation 40: 19-30.

Davis, P.

1998 The bioerosion of bird bones. International Journal of Osteoarchaeology 7: 388-401.

Elkin, D.

1995 Volume density of South American camelid skeletal parts. International Journal of Osteoarchaeology 5: 29-37.

1996 Arqueozoología de Quebrada Seca 3: indicadores de subsistencia humana temprana en la Puna Meridional Argentina. Tesis Doctoral. Universidad de Buenos Aires, Buenos Aires. 
Fernández-Jalvo, Y.; Sánchez-Chillón, B.; Andrews, P.; Fernández-López, S. y L. Alcalá Martínez

2002 Morphological taphonomic transformations of fossil bones in continental environments, and repercussions on their chemical composition. Archaeometry 44: 35361.

Fisher, J.

1995 Bone surface modifications in zooarchaeology. Journal of Archaeological Method and Theory 2: 7-68.

Gifford, D.

1981 Taphonomy and Paleoecology: a critical review of archaeology's sister disciplines. Advances in Archaeological Method and Theory 4: 365-438.

Jans, M.; Nielsen-Marsh, C.; Smith, C.; Collins, M. y H. Kars

2004 Characterisation of microbial attack on archaeological bone. Journal of Archaeological Science 31: 87-95.

Johnson, E.

1985 Current developments in bone technology. Advances in Archaeological Method and Theory 8: 157-235.

López, G.

2008 Arqueología de Cazadores y Pastores en Tierras Altas: Ocupaciones Humanas a lo largo del Holoceno en Pastos Grandes, Puna de Salta, Argentina. BAR South American Archaeology Series, Archaeopress, Oxford.

Lyman, R.

1994 Vertebrate Taphonomy. Cambridge University Press, Cambridge.

Marozzi, A.

2012 Tafonomía de vertebrados holocénicos del sitio arqueológico Cueva Salamanca 1 en la Puna Salada argentina. Tesina de Licenciatura. Universidad Nacional de Córdoba, Córdoba.

Marozzi, A. y M. Mondini

2010 Tafonomía de mamíferos holocenos del sitio arqueológico Cueva Salamanca 1 en la Puna catamarqueña. Poster presentado en las XXIII Jornadas Argentinas de Mastozoología, Sesión: Paleontología. Sociedad Argentina para el Estudio de los Mamíferos, Bahía Blanca. 
Marozzi, A.; Mondini, M.; Pintar, E. y M. Reigadas

2013 Hacia un estudio integral de los camélidos holocénicos en la Puna Salada: el caso de Cueva Salamanca 1, Antofagasta de la Sierra, Catamarca. Trabajo presentado en el III Congreso Nacional de Zooarqueología, Tilcara.

Martínez, J.

2005 Tecnología de cazadores en la Puna Meridional Argentina: el caso de Peñas de la Cruz 1. Mundo de Antes 4: 25-49.

Martínez, J.; Aschero, C.; Powell, J. y M. Rodríguez

2004 First Evidence of extinct megafauna in the Southern Argentinian Puna. Current Research in the Pleistocene 21: 104-06.

Martínez, J.; Aschero, C.; Powell, J. y P. Tchilinguirián

2007 A gap between extinct pleistocene megafaunal remains and Holocene burial contexts at achaeological sites in the Southern Argentinian Puna. Current Research in the Pleistocene 24: 60-62.

Martínez, J.; Mondini, M.; Pintar, E. y M. Reigadas

2010 Cazadores-recolectores tempranos de la Puna meridional argentina: avances en su estudio en Antofagasta de la Sierra (Pleistoceno final-Holoceno Temprano/medio). En Arqueología Argentina en el Bicentenario de la Revolución de Mayo, J. Bárcena y H. Chiavazza (eds.), pp. 1691-1696. FFyL-UNCu-INCIHUSA-CONICET, Mendoza.

Mengoni Goñalons, G.

2010 Zooarqueología en la práctica: algunos temas metodológicos. Xama 19: 83-113.

Mohn, M.

2010 Las ocupaciones humanas del sitio arqueológico Quebrada Seca 3 en Antofagasta de la Sierra. Tesis de Licenciatura. Universidad Nacional de Córdoba, Córdoba.

Mondini, M.

1995 Artiodactyl prey transport by foxes in Puna rock shelters. Current Anthropology 36: 520-24.

2001 Taphonomic action of foxes in Puna rockshelters: a case study in Antofagasta de la Sierra (Province of Catamarca, Argentina). En Ethnoarchaeology of Andean South America, Contributions to Archaeological Method and Theory, L. Kuznar (ed.), pp. 266-295. International Monographs in Prehistory, Ethnoarchaeological Series 4, Ann Arbor. 2002 Carnivore taphonomy and the early human occupations in the Andes. Journal of Archaeological Science 29: 791-801. 
Mondini, M.

2003 Formación del registro arqueofaunístico en abrigos rocosos de la Puna argentina. Tafonomía de carnívoros. Tesis Doctoral. Universidad de Buenos Aires, Buenos Aires. 2004 La comunidad de predadores en la Puna durante el Holoceno. Interacciones bióticas entre humanos y carnívoros. Relaciones de la Sociedad Argentina de Antropología XXIX: 183-209.

2005 Use of rockshelters by carnivores in the Puna. Implications for hunter-gatherer archaeology. Before Farming, the Archaeology and Anthropology of Hunter-Gatherers 2005/2 article 3 [online version] / 2:158-182 [print version].

2007 Tafonomía de vertebrados en la Puna Argentina: atrición y modificaciones óseas por carnívoros. En Human and Faunal Relationships Reviewed: An Archaeozoological Approach, E. Corona y J. Arroyo Cabrales (eds.), pp. 95-112. BAR International Series, Archaeopress, Oxford.

Mondini, M. y D. Elkin

2006 Cazadores-recolectores de la cuenca de Antofagasta de la Sierra (Puna Meridional Argentina): una perspectiva zooarqueológica y tafonómica. Cazadores y Recolectores del Cono Sur 1: 67-79.

2014 Holocene hunter-gatherers in the Puna. Integrating bones and other zooarchaeological evidence in Antofagasta de la Sierra (Argentina). En Hunter-gatherers from a High-elevation Desert: People of the Salt Puna (Northwest Argentina), E. Pintar (ed.), pp. 117-124. BAR International Series, Archaeopress, Oxford.

Mondini, M. y A. Muñoz

2008 Pumas as taphonomic agents: a comparative analysis of actualistic studies in the Neotropics. Quaternary International 180: 52-62.

Mondini, M.; Martínez, J.; Pintar, E. y M. Reigadas

2013 Middle Holocene foraging, mobility and landscape use in the southern Argentinean Puna: Hunter gatherers from Antofagasta de la Sierra, Catamarca, Argentina. Quaternary International 307: 66-73.

Mondini, M.; Marozzi, A. y E. Pintar

2015. Interacciones entre humanos y animales en la Puna Salada durante el Holoceno Medio: el caso de Cueva Salamanca 1, Antofagasta de la Sierra, Catamarca. Arqueología 21(1): 73-87.

Núñez, L.; Grosjean, M. e I. Cartajena

1999 Un ecorefugio oportunístico en la Puna de Atacama durante eventos áridos del Holoceno Medio. Estudios Atacameños 17: 125-174. 
Olivera, D.; Tchilinguirian, P. y L. Grana

2004 Paleoambiente y arqueología en la Puna Meridional argentina: archivos ambientales, escalas de análisis y registro arqueológico. Relaciones de la Sociedad Argentina de Antropología XXIX: 229-47.

Olivera, D.; Tchilinguirian, P. y M. de Aguirre

2006 Cultural and environmental evolution in the meridional sector of the Puna of Atacama during the Holocene. En Change in the Andes: Origins of Social Complexity, Pastoralism and Agriculture, H. Yacobaccio y D. Olivera (eds.), pp. 1524-1527. Archaeopress. Oxford.

Pintar, E.

2004 Cueva Salamanca 1: ocupaciones altitermales en la Puna Sur (Catamarca). Relaciones de la Sociedad Argentina de Antropología XXIX: 357-66.

2009 Un "ecorefugio" en la cuenca de la laguna de Antofagasta (Puna Salada), entre 7900 y 6200 AP. Arqueología 15: 85-108.

2012 Informe $6^{a}$ campaña a Cueva Salamanca 1 y prospección en la zona del Salar del Hombre Muerto: 11-23 de marzo. Informe de la campaña arqueológica de 2012. Preparado para la Dirección Provincial de Antropología, Secretaría de Estado de Cultura, Catamarca.

2014 Continuidades e hiatos ocupacionales durante el Holoceno Medio en el borde oriental de la Puna Salada, Antofagasta de la Sierra, Argentina. Chungara 46(1): 51-72.

Reigadas, M.

2006 Análisis de fibras animales para la definición de su estatus en el proceso de intensificación en la relación hombre-recurso animal: caso Quebrada Seca 3. CazadoresRecolectores del Cono Sur 1:111-124.

2010 Fibras animales arqueológicas: explorando una nueva agenda. Estudio de la estructura física celular de las fibras. En Arqueología Argentina en el Bicentenario de la Revolución de Mayo, J. Bárcena y H. Chiavazza (eds.), pp. 2065-2069. FFyL-UNCuINCIHUSA-CONICET, Mendoza.

Rodríguez, $\mathrm{M}$.

2004 Cambios en el uso de los recursos vegetales durante el Holoceno en la Puna meridional argentina. Chungara 36 (Volumen especial tomo 1): 403-413.

Tchilinguirian, P. y D. Olivera

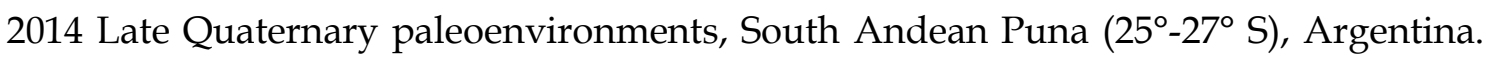
En Hunter-gatherers from a High-elevation Desert: People of the Salt Puna (Northwest Argentina), E. Pintar (ed.), pp. 43-69. BAR International Series, Archaeopress, Oxford. 
Tchilinguirian, P. y M. Morales

2013 Mid-Holocene paleoenvironments in Northwestern Argentina: main patterns and discrepancies. Quaternary International 307: 14-23.

Tchilinguirian, P.; Olivera, D. y L. Grana

2005 Paleoambientes sedimentarios y su aplicación en arqueología Antofagasta de la Sierra, Catamarca. Trabajo presentado en el Primer Congreso Argentino de Arqueometría. Facultad de Humanidades y Artes, Universidad Nacional de Rosario.

Urquiza, S.

2008 Entomología y química en el contexto arqueológico: nuevos elementos para el entendimiento de la historia tafonómica del registro arqueofaunístico de Antofagasta de la Sierra, Catamarca (Argentina). En Zooarqueología a Principios del Siglo XXI: Aportes Teórico-Metodológicos y Casos de Estudio, M. Gutiérrez; M. de Nigris; P. Fernández; M. Giardina, A. Gil; A. Izeta; G. Neme y H. Yacobaccio (eds.), pp. 429-437. Ediciones del Espinillo, Buenos Aires.

Urquiza, S.; Cuenya, P. y C. Aschero

2009 Química del suelo: un aporte a la tafonomía en Antofagasta de la Sierra, Catamarca. En Arqueometría Latinoamericana. Segundo Congreso Argentino y Primero Latinoamericano, O. Palacios, C. Vázquez, T. Palacios y E. Cabanillas (eds.), pp. 209-214. Comisión Nacional de Energía Atómica, Buenos Aires.

Yacobaccio, $\mathrm{H}$.

2013 Towards a Human Ecology for the Middle Holocene in the Southern Puna. Quaternary International 307: 24-30.

Yacobaccio, H.; Catá, M.; Morales, M.; Joly, D. y C. Azcune 2007 Ocupaciones humanas tempranas en la Puna de Atacama: el alero Hornillos 2 (Susques, Jujuy). En Artefactos Líticos, Movilidad y Funcionalidad de Sitios: Problemas y Perspectivas, P. Ecola y S. Hocsman (eds.), pp. 1-10. BAR International Series, Archaeopress, Oxford. 